\title{
Letter to the President concerning BMA enquiry into boxing injuries
}

\section{Dear Professor Sims}

The British Medical Association (BMA) Board of Science and Education Steering Group on Boxing would be grateful for your assistance in its current investigation into boxing injuries.

Since 1982 the BMA's policy has been that it should work towards an ultimate ban on boxing. In response to a 1982 Annual Representative Meeting resolution which stated:

"That in view of the proven ocular and brain damage resulting from professional boxing, the Association should campaign for its abolition",

the BMA Board of Science and Education set up a Working Party to review the evidence on brain and eye damage as a result of boxing injuries. The Working Party concluded in its final report published in 1984 that substantial damage occurred to the eye and brain in amateur and professional boxers.

Since 1984, there have been certain developments within the sport and in attitudes to the sport as well as advances in the medical field such as brain scanning techniques, enabling detection of abnormalities before clinical signs and symptoms appear. The BMA Board of Science and Education therefore believes that the 1984 boxing report should now be revised to incorporate recent data. The scope of such a study would include a review of the latest medical evidence, consideration of the adverse health effects of boxing in the light of developments in medical technology and an update of the statistics in relation to boxing injuries and deaths.

Although the Association has a large database of scientific and medical evidence on injuries sustained through boxing, it is likely that many injuries, in particular cases of dementia pugilistica, are not widely reported. To assist our investigations I am therefore writing to request information on boxers who are, or have been, under the care of your members, in particular, evidence of those who may exhibit dementia pugilistica. Any submissions will be treated with the strictest confidence, although the information may be used to produce anonymised case studies or informal evidence of damage associated with boxing, whether acute or chronic. I would be grateful if you could inform your members of the current work of the Association in order that they may submit evidence to the BMA if they wish to do so.

If your members would like to submit evidence to the Association regarding boxing injuries they should contact Sallie Robins at BMA (tel: 071-383 6225) who will forward a short questionnaire for their completion.

Thank you in advance for your assistance in this project and I would be happy to answer any queries you or your members may have.

Dr G. W. ROBERTS Member

BMA Board of Science and Education Steering Group on Boxing 